\title{
iPepper: Intelligent Pepper Grading and Quality Assurance System
}

\author{
D.N.F Awang Iskandar ${ }^{\# 1}$, Rubiyah Baini ${ }^{2}$, Alvin Yeo Wee ${ }^{\# 3}$, Shapiee Abdul Rahman ${ }^{\# 4}$ and Ahmad Hadinata Fauzi ${ }^{\# 5}$ \\ ${ }^{\#}$ Faculty of Computer Science and \\ Information Technology, \\ Universiti Malaysia Sarawak, \\ 94300 Kota Samarahan, Sarawak, Malaysia. \\ ${ }^{1}$ dnfaiz@fit.unimas.my \\ 3alvin@fit.unimas.my \\ ${ }^{4}$ sar@fit.unimas.my \\ ${ }^{5}$ hadinata@fit.unimas.my \\ ${ }^{*}$ Faculty of Engineering, \\ Universiti Malaysia Sarawak, \\ 94300 Kota Samarahan, Sarawak, Malaysia. \\ ${ }^{2}$ ruby@feng.unimas.my
}

\begin{abstract}
Pepper is a key export of the state of Sarawak (Malaysian Borneo); it produces $98 \%$ of Malaysia's pepper. At present, processed pepper berries are graded manually. This process is time consuming and error prone as it is very much dependent on the experience of the pepper grader. To overcome these weaknesses, we propose a Pepper Grading System which employs image processing and machine learning approaches using image features and moisture content data of the pepper berries. For instance, from initial tests, a high correlation between the grade of pepper berries to the colour features has been detected. Using existing machine learning algorithms in WEKA, we have obtained a $100 \%$ accuracy in categorising the pepper berries into the correct grades. In addition, moisture content and colourometer readings provide another 2 other parameters which may complement the image features in accurately classifying the berries into the right grades.
\end{abstract}

Keywords - component; image processing and analysis, computer vision, agricultural sciences

\section{INTRODUCTION}

Pepper, the world's most widely used spice for food flavouring, is the fruit of the tropical climbing vine Piper Nigrum L., native to south-western India. In Malaysia, pepper cultivation dates back to 1856 but more extensive planting started in the 1900s. Currently, Malaysia ranks fifth after Vietnam, India, Indonesia, and Brazil in terms of pepper production. Nearly $98 \%$ of Malaysian pepper is produced in the state of Sarawak on Borneo Island.

About $95 \%$ of the pepper traded globally is in the form of black and white pepper. The remaining $5 \%$ is made up of pepper oleoresin, pepper oil, green pepper and ground pepper. Practically, all Malaysian pepper exports are in the form of black and white pepper which is produced generally in the ratio of 70:30 respectively. Malaysian Pepper Board (MPB), a statutory body established under the Malaysian Pepper Board
Act 2006, oversees all pepper related activities in the country, including the grading of all pepper for export [3]. Buyers of processed Malaysian pepper are assured of receiving the quality of pepper that they agreed to purchase as per the grade certificates and colour labels issued by the MPB. This serves as an assurance that Malaysian pepper exporters will deliver pepper that meets the specifications of that grade.

Processed pepper berries are graded by size, colour, moisture content, and extraneous matter content. Six grades of white pepper berries and five grades of black pepper berries are used. Currently, the use of an automatic commercial colour sorter for the pepper berries is only for discriminating one grade, which is the best white pepper namely "creamy white". However, the sorting of pepper berries into the other grades are still being carried out manually in the lab. Thus, our research focuses on grading these remaining grades that are specified in Table I. MPB is seeking alternative methods to execute the grading process more accurately and more reliably. We believe the manual, time-consuming and error-prone pepper grading task can be improved significantly using image processing, machine learning techniques and statistical approaches.

In this paper, we propose a framework for an intelligent and automatic pepper grading system to grade the white pepper berries according to its respective grades based on the ISO pepper grading standard. Ultimately, this project could be extended as a framework for grading the black pepper berries as well as other related agricultural products. The main difference of this framework is that we include image processing approaches complemented with chemical content analysis to automatically grade the pepper.

The remainder of this paper is organised as follows. In Section II, we discuss the related work. In Section III we describe the framework and methodology used. In Section IV, we present our initial finding and in Section V, we conclude our findings and provide suggestions for future work. 